\title{
Development of Database of The Abu Lais' Thought Regarding Hadith
}

\author{
$1^{\text {st }}$ Nawir Yuslem ${ }^{1}, 2^{\text {nd }}$ Muhammad Irwan Padli Nasution ${ }^{1}, 3^{\text {rd }}$ Ahmad Muhaisin B \\ Syarbaini ${ }^{1}$ \\ \{nawiryuslem15@gmail.com ${ }^{1}$, irwannst@uinsu.ac.id ${ }^{1}$ \} \\ Universitas Islam Negeri Sumatera Utara, Indonesia ${ }^{1}$
}

\begin{abstract}
As a Moslem, there is no doubt that the Quran and Hadith are the highest references in Islam. Contextualization of Hadith of Abu Lais contributed significantly to the dynamics of Islamic law. With the contextualization of Hadith of Abu Lais is effective in making Hadiths relevant to the development of context so that the Islamic law it contains becomes dynamic and relevant. Along with the development of this era required electronic media that can store data and accurate information about his thought. Information Communication and Technology (ICT) innovation can be developed an online database that can provide information with accurate, fast and relevant and efficient use of storage space to be accessible from anywhere and anytime, access by using a Personal Computer and also mobile devices. Thus the documentation and dissemination of Abu Lais thought will be stored online and can be known by many people around the world.
\end{abstract}

Keywords: Abu Lais; Contextualization of Hadith; database; information; ICT

\section{Introduction}

In Islam, the hadith is mashdar al-hukm (source of legal decision). The hadith, which is what was reported from the Prophet, in the form of words, deeds, stipulations of physical nature or moral character, travel after being appointed as a Prophet and sometimes also before, so that the meaning of the hadith here is as mean as the Sunnah. The Hadith of the Prophet believed by Muslims as the most tangible form of doctrine and a realization of the Islamic teachings contained in the Quran As a Muslim, there is no doubt that the Quran and hadith are the highest references in Islam. All aspects of Islamic teachings such as' aqidah, worship, muamalah, politics, economy, law and so on should refer to these two main sources. This is because Allah Almighty has explained that the Quran is a guide book for human beings containing various explanations that make people able to distinguish between good and bad.The legitimacy of the legitimacy of hadith or sunnah as the basis of religion is based on many words of Allah Swt and is a logical consequence given that the Messenger of Allah was the bearer of revelation so it is certain that he who most understand the verses revealed to him. Nevertheless, it can not be denied that the distance between the Messenger of Allah and us. Which is far adrift over 1400 years has led to the various order and condition of today's society has characteristics different from the community faced by the Messenger of Allah on both customs and habits of society and the conditions experienced by society today. Therefore, it may be the context or circumstances that exist at that time into consideration why a law 
established by Prophet Muhammad Saw no longer found or there have been changes that are even very drastic in the current of. Thus the question arises as to whether a hadith can be contextualized or can be presented with a different understanding because it has a different context between the time of the birth of a hadith with the context of society at this time or precisely that context difference is not the reason for the change of the provisions contained in hadiths of Prophet Muhammad Saw. If it is assumed that the context difference is not the reason for the change of provisions contained in the hadiths of the Prophet Muhammad, it is very hard to negate the negative impact of that where such a viewpoint will actually narrow the thinking space of Muslims from one side and on the other hand will complicate the life of Muslims itself. For example, for example the case that occurred at the time of the Messenger of Allah. Where there has been a very high price spike in the market. This causes the purchasing power of the people to weaken and many of the materials that are the basic needs of society can not afford to buy. Finally, the Companions came to the Messenger of Allah. (as the Prophet and the leader) To ask the Messenger of Allah to set the price of the goods. Therefore, if it is assumed that the hadiths of the Prophet Muhammad may be reinterpreted through the method of contextualizing the hadith especially in the field of Islamic law, does the contextualization not have the potential to crash established provisions in the study of ushul fiqh or the rules contained in the study of the sciences of Sharia as described above. Thus, it is very important to discuss deeply about the concept of contextualization of hadith which aims to bridge between the hadith text and socio-cultural context of society that develops in the sense of studying the necessity of contextualization of the hadith itself and how the procedure must be passed in contextualizing a hadith. Abu Lais is a scholar of hadith who has consistently studied Hadith since bachelor graduate from University of Madinah, Magister from umm Al-Qura University, Mecca and Doctoral at Umm Al-Qura University, Mecca. He gives a very interesting view of the study of hadith in his book 'Ulum Al-Hadith: Asiluha wa Mu'asiruha. This book contains the theory of contextualization and its application in understanding the legal traditions and to see how far the theory can respond to the dynamics of Islamic law. Along with the development of Information Communication and Technology (ICT), can be developed a database that contains about complete information about the thinking of Abu Lais. Thus, the use of database technology will be useful to save time and cost because with a computerized database can stores a lot of information such as printing, loading, displaying accurate data, facilitating data access, isolating data to be standardized, reducing data redundancy and data inconsistency. In this case the selection of appropriate database technology is necessary so that Abu Lais's thoughts can be known by many people and can be accessed easily, more quickly and cheaply.

\section{The Abu Lais' Thought Regarding Haditsh}

Abu Lais is a scholar of hadith who has consistently studied Hadith from undergraduate to $\mathrm{PhD}$. His full name is Abu Lais Al-Khair Al-Aba in. Born in India precisely in the City of Khairabad in 1953. Abu Lais's intelligence has been seen since young and proven by his appointment as a teacher and mufti at the age of 17 years in India. From 2000 to 2009, he was appointed Professor of Quran and Sunnah at the International Islamic University of Malaysia and regular teaching of Hadith to all undergraduate, Master and PhD students. Achievements and services of Abu Lais in the world of hadith is very much and well known among scientists hadith today, so it is not surprising if he was given the honor to occupy some important 
position in the world of contemporary Islamic education, especially in the study of the hadith. Among them are: 1). Members of the Secretariat General of International Hadith Symposium at College of Islamic and Arabic Studies, Dubai (2011 - 2013), 2). General Counsel of Islamic Journal Institute of the University of Sultan Sharif Ali, Brunei Darussalam (2011 - present), 3). An Academic Advisor for the Evaluation Doctoral in Hadis project at the Faculty of Shariah, Kuwait University in 2013. Among his most important works in the study of the science of hadith are: 1). The principle of An-Niza m Al-Ma li Wa Al-Iqtisa in Fil Quran, 2) .Tririj Al-Hadith, 3). 'Ulum Al-Hadith: Asiluha wa Mu'asiruha, 4). Mu'jam Al-Mustalahat AlHadis | iyyah, 5).Ittijahat Fi Dirasatissunah: Qadimiha Wa Hadisiha, and many more of his works including articles and papers. Book of 'Ulum Al-Hadith; Asiluha wa Mu'asiruha by Abu Lais is a unique book when compared to Hadith books written by scientists of today's tradition. On one side of the book is a must-have book hadith that describes the study related to the discipline of hadith as the must be hadith. But on the other hand, Abu lais prepared a chapter in his book in the last chapter on how to interact (ta'amul) with the traditions that had been present more than 1400 years ago without denying or negating the facts and contemporary reality on this day that is happening around the Moslems that have differences even contrary to the situation and conditions that occurred in the early Islamic generation. According to Abu Lais, the correct view of the sunnah is to believe that there are some sunnah that are eternal and do not accept any change and on the other there is sunnah that is adaptive to certain contexts and circumstances so that it can accept the change with the occurrence of changing circumstances or context in the middle - in the Islamic community.

Even according to Abu Lais, there are many stories that support that the contextualization of the hadith is a necessity. Among them are the words of the Messenger of Allah. :

Meaning:

$$
\text { لا يصلّينّ أحدكم العصر إلا في بني قريظة }
$$

"Let not one of you perform the prayer ashar but in the village of Bani Quraizhah." (HR.Bukhari and Muslim)

Hearing these traditions, the friends who were sent by the Prophet Muhammad to the Bani Quraizah have a different attitude. Some of them are delaying the ashar prayer even when the ashar time is up because it is based on the text of the hadith. But some friends that others keep working Asr prayer at the time though not arrived at the destination due to some friends, the tradition is spoken by the Prophet is not intended to set a time limit Asr prayer but an order to hasten toward the destination and ultimately Prophet Muhammad justify both attitudes taken by the Companions. Based on that history can be concluded that the method of understanding the meaning of the hadith is the purpose behind these traditions have occurred since the time of the Prophet Muhammad so that contextualization is new in the study of that attempts to the contextually is a must and this assessment is very helpful in that speak about the law. A genius at the same thoroughness Abu Lais in integrating the study of hadith and Sharia sciences so as to generate a theory or rules of a new, independent outside of the rules contained in the disciplines of hadith and ushul fiqh itself.

\section{Database Technology}


A database is a collection of information stored in the computer systematically so it can be checked using a computer program to obtain information from the database The software used to manage and call the database is called the database management system (database management system). The database system can be learned in information science. A database is a complete set of operational data records of an organization or company, organized and stored in an integrated manner using a particular method so as to meet the optimal information required by users. The term database refers to a collection of interconnected data, and the software should refer to a database management system so that many administrators and programmers use database terms for both meanings. Database technology is naturally very flexible and accompanied by high capabilities to be configured/tailored to company needs and simplicity to make modifications/changes and give full confidence in the implementation and continuity of handling the company's operational system can be achieved easily and effectively. A functional device provided by database technology will also make administrative tasks very minimal. Database technology continues to evolve in line with the research of experts. Juan Loaiza has been pounding away at Oracle Database for more than 27 years, helping refine the technology as it exists today. With that perspective, Loaiza thinks the careers of developers, architects, and IT implementers will depend on how well they prepare for the "big waves sweeping through the database industry." So here are 10 transformational database technologies that Loaiza thinks developers, architects, and other IT pros need to track. [3]

\subsection{Engineered Database Systems}

Building a database from scratch is a simple idea, where Oracle with its hardware can maximize the software to run the Oracle database. for example, the system moves query processing directly to storage so analytics can run quickly. Loaiza - and Oracle - are people who truly believe in this approach, but many still don't know whether this will be successful in the industry as is the case with some of the trends below.Oracle has thousands of customers in production, but no other industry has followed in its footsteps.

\subsection{In-Memory Database}

There isn't much about this, where each database vendor adds memory to its line. use of data structures and algorithms on data in memory, where databases can run analytics 10.20 or can reach 100 times faster than physical based databases. where speed makes people ask, because analysts can repeat "what if" questions where they will get answers in seconds, not hours.

Loaiza said that in offering Oracle this "dual format architecture" is unique - where there is a single database that uses an approach depending on the user: line analysis for OLTP, and column-in-memory analysis for analytics. In-memory is part of the Oracle Database $12 \mathrm{c}$ architecture, it can be said that companies have not changed the applications running on Oracle Database, and the features they expect to get, such as high availability and scalability. From the on-disk format to the memory database, "the entire industry will be there," Loaiza said.

\subsection{Software in Silicon}

"This is not just a product feature. It's really a computer science advance," Loaiza says.

Oracle calls the approach "software in silicon"-embedding algorithms directly onto microprocessors. The idea is that processors can't just keep adding ever-more cores and threads, so speed and performance will come from putting algorithms to accelerate core tasks 
such as encryption and compression directly onto the chip. Loaiza cites three aspects of this advance. First, SQL in silicon accelerates database in-memory performance. Second, capacity in silicon can get a lot more data into memory using on-processor tactics such as real-time decompression. Third, encryption support in silicon can help improve security as workloads move to in-memory, because without such protection in-memory could be less secure than data on disk. "It's an advance for the whole industry on how database processing works, and how chips are designed," Loaiza says. "You'll see more of these products appear as other vendors start copying this technology."

\subsection{Big Data Linked to Existing Data}

Many companies use Big Data in strategies such as the Internet of Things, or clickstream web tracking data. but more knowledge about Big Data comes from combining new Big Data with pre-existing data companies. questions will come to the pro database: "How can existing Big Data with operational data be integrated?" Loaiza said. He put forward two Oracle technologies as examples that can help. First, Oracle Big Data Appliance is a system that runs Apache Hadoop and Spark, allowing IT teams to build large data systems much faster and at a much lower cost than building it themselves. Two, Oracle Big Data SQL allows analysts to run massively parallel, full SQL SQL queries across relational, Hadoop, and NoSQL data. Oracle SQL is more sophisticated than what is generally run on this large data set, Loaiza said. The aim is to "make it simple and efficient to integrate all this big data together.

\subsection{Sharding for Easier Global-Scale OLTP}

We have said from the start that large web companies with users reaching hundreds of millions to billions are very dependent on wasted databases; to manage one billion users they not only have large databases, they make the database broken so that it becomes a more manageable element, but the company can still question all the fractions. Sharding technology was developed several years ago and is easy to use using NoSQL. "This is one reason many web companies like NoSQL," Loaiza said. Oracle plans to offer "genuine sharding" in Oracle Database, Loaiza said, because in the past users had to take manual steps to simulate sharding in Oracle Database. Genuine sharding will allow IT to manage fractions, while getting the usual benefits from Oracle Database, such as high availability and security features.

\subsection{Complete Data Protection}

When disk-based database backups came on the scene about a decade ago, they brought two big advances over tape: more accessibility to data and deduplication that reduced the volume of data. "And that's where it stopped in the last decade," Loaiza says. Increasingly, the expectation will be that data backups happen constantly, in real time, so that data never gets lost. With batch-oriented, disk-based backups, data can be lost between backups. That doesn't cut it in today's digital business models. "Nobody wants to lose data." Loaiza says. "It's pretty much impossible to go to financial users and say 'I've lost your data.' No one wants to lose their seat on an airplane, or their day's worth of shopping." Oracle meets this need with an approach similar to its engineered systems, using specialized algorithms on custom hardware called Zero Data Loss Recovery Appliance. In addition to preventing data loss, the appliance has minimum impact on production servers because it backs up only the changes to the database, rather than copying a whole database. It has database-aware recovery that validates data as it backs up, and it offers cloud-scale protection, so a single appliance can back up a whole data center. 


\subsection{JSON is currently integrated with SQL}

According to Loaiza, JSON is very well known in the field of developers who can represent data and can replace XML that is used to format data with complex structures, for example user profiles or web pages. The NoSQL database project invites JSON because JSON is widely used by developers in making their applications. Currently JSON data can be stored natively as a column on the Oracle database. Thus, JSON data can be accessed via SQL very easily and the database pro can use that data to work on various relational database tasks. "If you look at NoSQL databases, they kind of had two technologies that were really interesting one was sharding, the other was JSON," Loaiza says. "We've now introduced those into relational databases."

\subsection{Container Databases}

More than two decades Virtualization has been widely used, and has given way to lighter and heavier container-based virtualization. With Oracle Database multitenancy, container technology directly goes into the relational database, not visualizing at the operating system level. With container databases, one container manages many "pluggable" databases. Each database that has been installed with container technology considers having its own personal resources, but actually shares it as part of one container, which makes managing and scaling easier. The container database is useful for consolidating many databases in a company to reduce costs, Loaiza said. Another function is that it can help reduce software administration costs, because there is less software to manage than OS-based virtualization. OS-based virtualization reduces hardware requirements by increasing server utilization rates, but increases the administrative burden of software, because each virtual machine has copies of all software.

\subsection{Cloud-Based Databases}

The testing team and the development team want to have a database environment that can run fast without having to wait for IT to manage it. The company wants its database to be upgraded immediately if the application is popular because if it fails, the company will close and move on to the next idea. They want the new performance and security features in a database to be used and will pay the technology team to be able to build new applications and be able to analyze new data, rather than having to fix the servers in the company's data center. this is because of the increase in cloud-based databases. The existence of a system such as Oracle's Exadata Cloud Service Database that provides Oracle Database performance that can run on Oracle Exadate, cloud-based databases can be easily obtained and with various benefits, such as fast provisioning, continuous updates, availability and subscription pricing. "It's moving to the cloud but taking with you all the advantages that we've built during the past 40 years instead of going to some primitive database in the cloud," Loaiza says.

\subsection{Coexistence of Cloud and On-Premises Databases}

With the cloud, the pro database can run on a local system. Often a company rules to be able to store data on its data center and also often make special applications to do this task. This makes IT use modern applications. Oracle can overcome this by creating a system, called Oracle Cloud Machines, which can run the database exactly as it does on the Oracle Cloud, but which is located in the company's own data center. IT pays for Oracle Cloud Machine as a subscription, Oracle pro can manage remotely, and capacity can be increased up and down depending on needs; the only difference is that the device is behind your firewall. 


\section{Abu Lais' Thought Cloud-Based Databases}

There are several advantages of Cloud Storage, namely (1). Usability: There is a desktop folder for Mac and PC on all cloud storage services that can be used by users to drop files between local storage and the cloud, (2). Bandwidth: Sending e-mails to individuals can be avoided and sending web messages to recipients via e-mail is replaced, (3). Accessibility: Can access files stored from anywhere using an Internet connection; (4). Disaster Recovery: Companies are expected to have an emergency backup plan that can be used in an emergency and for backup plans that can store copies of important files can use Cloud storage that can be accessed using an internet connection; (5). Cost Savings: Using cloud storage can reduce annual operating costs because to store data internally requires only about 3 cents per gigabyte. because internal power is no longer needed, users can find out about additional cost savings.

Figure 1. Abu Lais' Thought Cloud-Based Databases

From the advantages of cloud computing and e-collaboration is more suitable for

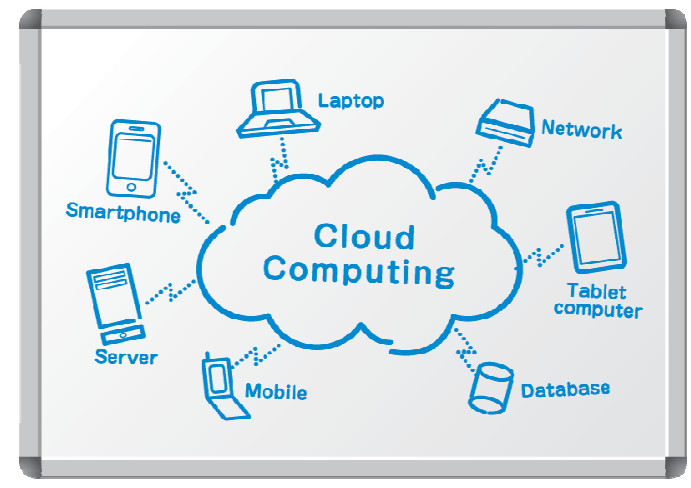

Database of The Abu Lais' Thought Regarding Hadith. Cloud databases are also known as database as a service (DBaaS), since they are often offered as a managed serviceAs shown in Figure 1, database containing information about Abu Lais' Though is placed on the cloud so that it can be accessed from anywhere. Devices for access to the database can be used from a wide range of Personal computers to smartphones.

\section{Conclusion}

The Abu Lais' Thought Regarding Hadith is using cloud-based databases will be easy to develop and more to increase to share all the information over the world everywhere. Devices for access to the database can be used from a wide range of Personal Computers to any other mobile devices like smartphones. 
Acknowledgements. This paper in conjuction with the 2nd International Conference on Quran-Hadith, Information Technology and Media: Challenges and Opportunities (ICONQUHAS 2018).

\section{References}

[1] Lais, Abu. 'Ulum Al-Hadis : Ashiluha wa Mu'ashiruha, edition VI, Kuala Lumpur : International Islamic University of Malaysia, 2009.

[2] M.I.P. Nasution, S. Dewi Andriana, P. Diana Syafitri, E. Rahayu and M.R.Lubis, "Mobile device interfaces illiterate" Technology, Informatics, Management, Engineering \&Environment (TIME-E), 2015 International Conference on, Samosir, 2015, pp. 117-120, doi= $\{10.1109 /$ TIME-E.2015.7389758\}

[3] https://www.oracle.com/corporate/features/ten-database-technologies.html.(Last visited:30.06.2018)

[4] Nasution, Muhammad Irwan Padli, Urgensi Keamanan Pada Sistem Informasi, 2008, Jurnal Iqra' Volume 02 Nomor 02

[5] https://www.oracle.com/us/assets/dbim-infographic-2680715.pdf, (Last visited:30.06.2018) 